\title{
Invasive red lionfish Pterois volitans blow directed jets of water at prey fish
}

\author{
Mark A. Albins ${ }^{1, *}$, Patrick J. Lyons ${ }^{2}$ \\ ${ }^{1}$ Department of Zoology, Oregon State University, 3029 Cordley Hall, Corvallis, Oregon 97331, USA \\ ${ }^{2}$ Department of Ecology and Evolution, SUNY at Stony Brook, 650 Life Sciences Building, Stony Brook, New York 11794, USA
}

ABSTRACT: Field and laboratory observations of feeding by invasive Pacific red lionfish Pterois volitans were conducted during June through August of 2008, 2009 and 2010 near Lee Stocking Island, Bahamas. Observations of this invasive marine predator revealed a previously undocumented piscivorous behavior. While slowly approaching prey fish, lionfish produce jets of water directed toward their prey. These jets may confuse or distract prey, and often result in prey fish facing the attacking lionfish, increasing the probability of head-first capture and swallowing. While a variety of fishes are reported to create directed water jets, to our knowledge, this is the first report of a fish that does so during the capture of fish prey. This behavior may confer a high degree of predatory efficiency, and thus contribute to the dramatic success of this Pacific invader of tropical Western Atlantic and Caribbean coral reefs.

KEY WORDS: Lionfish · Invasive species · Predation · Piscivory · Prey naïveté · Marine fishes

\section{Resale or republication not permitted without} written consent of the publisher

\section{INTRODUCTION}

A primary goal of invasion biology is to understand how characteristics of non-native species determine their degree of success in invaded communities. Often, biotic invasions are facilitated by specific traits or behaviors that allow invasive species to avoid predators or parasites, out-compete native species, or be particularly efficient predators (Holway \& Suarez 1999). Here we describe a unique feeding behavior in a particularly successful invasive marine predator. The novelty of this behavior in the invaded community

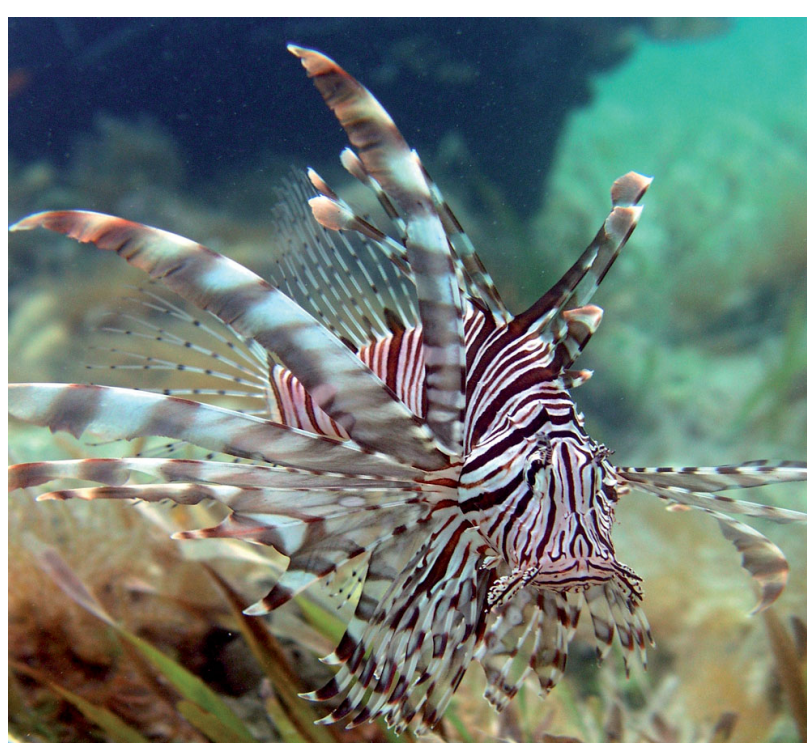

Pacific lionfish Pterois volitans in a seagrass bed in the Bahamas.

Photo: Timothy J. Pusack, Oregon State University

may confer a high degree of predatory efficiency and contribute to the dramatic success of this invasion.

The Pacific red lionfish Pterois volitans, introduced to the Atlantic near Florida during the mid-1980s, has rapidly spread across much of the Western Atlantic and Caribbean (Schofield 2009, 2010), where they have reached substantially higher densities (Green \& Côté 2009) and larger maximum sizes (Morris \& Whitfield 2009) than reported in their native Pacific range (Schiel et al. 1986, Randall et al. 1990, Fishelson 1997). Lionfish feed on a wide diversity of native Atlantic reef fishes and crustaceans (Morris \& Akins 
2009), and can reduce the abundance (by over 90\%) and species richness (by nearly 5 species) of small native coral-reef fishes on patch reefs (Albins \& Hixon 2008, M. A. Albins unpubl.). Lionfish also have stronger effects on native prey (2.5-fold) and grow considerably faster (6-fold) than a similarly sized native predator, the coney grouper (M. A. Albins unpubl.). Lionfish appear to be a particularly successful invader with strong effects on native communities, and may comprise one of the most damaging marine invasions to date (Sutherland et al. 2010, Albins \& Hixon 2011).

The success of lionfish in the invaded range is likely augmented by a number of physiological, morphological, and behavioral characteristics that confer protection from native predators, and allow lionfish to be particularly effective predators (Albins \& Hixon 2011, M. A. Albins unpubl.). Lionfish are well defended by venomous dorsal, pelvic and anal fin spines, which likely confer some degree of protection from native predators (Morris 2009, Morris \& Whitfield 2009). They also display a combination of slow movement, disruptive barred light-dark color pattern, numerous elongated fin rays, and a variety of fleshy and bony projections. These traits may reduce the detectability of lionfish by both predators and prey (Albins \& Hixon 2011). Lionfish herd and corner prey fishes with oversized fanlike pectoral fins (Allen \& Eschmeyer 1973, Fishelson 1997), and have been observed hunting in conspecific groups (Kendall 1990, authors' pers. obs.). Here we describe a newly discovered feeding strategy of invasive lionfish which has not, to our knowledge, been described for any other piscivore, and which may contribute to their dramatic success as an invader of Atlantic and Caribbean coral reefs.

\section{MATERIALS AND METHODS}

\section{Field observations}

Initial observations of the behaviors described here were made by SCUBA divers on shallow coral reefs of the Exuma Cays near Lee Stocking Island, Bahamas, where we have been conducting long-term studies of the lionfish invasion. These initial observations were made opportunistically during the course of related work, and are therefore presented as anecdotal data. We also present supplementary quantitative field data which was collected as part of a larger, inter-ocean, comparative study of lionfish time-budgets (K. Cure et al. unpubl.), in which individual lionfish were observed for 10 min intervals in both the Atlantic $(n=762)$ and the Pacific ( $\mathrm{n}=357$ ), and a variety of behaviors (including blowing water jets at prey fish) were recorded.

\section{Aquarium observations and feeding trials}

Field observations were supplemented by a series of ad-hoc feeding trials in aquaria. Lionfish and the native gobies Coryphopterus glaucofraenum and Gnatholepis thompsoni were captured using hand nets from coral reefs and seagrass beds. Previous field and aquarium observations indicated that these 2 species of goby were readily eaten by lionfish. Lionfish and gobies were acclimated to $190 \mathrm{l}$ flowthrough aquaria. After lionfish were acclimated to aquaria (i.e. would accept meals), observations of predation events and unsuccessful strikes were filmed using digital video cameras.

In an initial set of feeding trials, lionfish were presented gobies in an aquarium lacking shelter $(\mathrm{n}=8$ trials using 8 different lionfish). We then presented lionfish with gobies in transparent containers within the aquaria so that the lionfish could see the prey, but could not consume it ( $\mathrm{n}=4$ trials using 2 different lionfish). This also provided control over the location of the goby within the aquarium. We then conducted trials in which a lionfish was presented with prey in a transparent container, during which a glass pipette was used to release food-grade dye in front of the mouth of the lionfish to better visualize the speed and direction of the water jets ( $\mathrm{n}=6$ trials using a single lionfish).

Digital videos (Canon G9, $1024 \times 768$ pixels, 15 frames per second [fps]) of all feeding trials were examined to measure characteristics of water jets including the number and rate of water jet pulses. Additionally, video taken during the food-dye trials was analyzed using the image editing software GIMP 2.6 to estimate the speed and maximum distance of water jets. The speed of each water jet pulse for which a clear front was visible in the dye stream ( $=13)$, was estimated over the distance from 1 to $5 \mathrm{~cm}$ in front of the mouth of the lionfish. Distances in videos were calibrated using objects of known size (e.g. petri dishes, tubes). Elapsed times were measured using the known frame rate (15 fps) of the camera.

\section{RESULTS}

\section{General description of behavior}

While approaching prey fish in both the field and in aquaria, lionfish typically faced the prey, flared their 
pectoral fins perpendicular to their longitudinal axis, undulated their dorsal spines, and moved within striking distance very slowly using short, small caudal-fin thrusts. During this approach, lionfish often produced a strong, pulsed, jet of water via buccal compression, directed towards the target fish (Fig. 1, Movie S1 available at www.int-res.com/articles/suppl/m448 p001_supp/). This behavior occurred during $23.2 \%$ of all field observations of actively hunting lionfish, and during $100 \%$ of all aquarium feeding trials in which gobies were exposed to the lionfish. The pulsed water jet often appeared to increase in frequency and intensity as the lionfish approached the prey, and appeared to be matched closely to the frequency and intensity of the caudal-fin thrusts. The opposing forces of the forward thrust created by the caudal fin and the backwards thrust created by the water jet were apparently balanced as the lionfish maintained position or moved slightly forward with each pulse in all field and aquarium observations.

\section{Field observations}

Lionfish across a range of body sizes $(5$ to $30 \mathrm{~cm}$ total length [TL]) produced these water jets while hunting a variety of prey fishes in the field. Lionfish were observed directing pulsed jets of water at cryptic, benthic species such as gobies (e.g. Coryphopterus glaucofraenum) and blennies (e.g. Malacoctenus triangulatus), mobile swimmers such as wrasses (e.g. Halichoeres garnoti and H. bivitattus) and parrotfishes (e.g. Scarus iseri and Sparisoma aurofraenatum), and nocturnal, hole-dwelling species such as cardinalfishes (e.g. Apogon townsendi). While lionfish hunted and consumed other species such as damselfishes Stegastes partitus and surgeonfishes Acanthurus sp., they were not observed to direct jets of water at them. Hunting lionfish that produced water jets were, on average, between 0.59 and $2.93 \mathrm{~cm}$ TL (95\% CI) smaller than hunting lionfish that did not produce water jets (Welch Two Sample
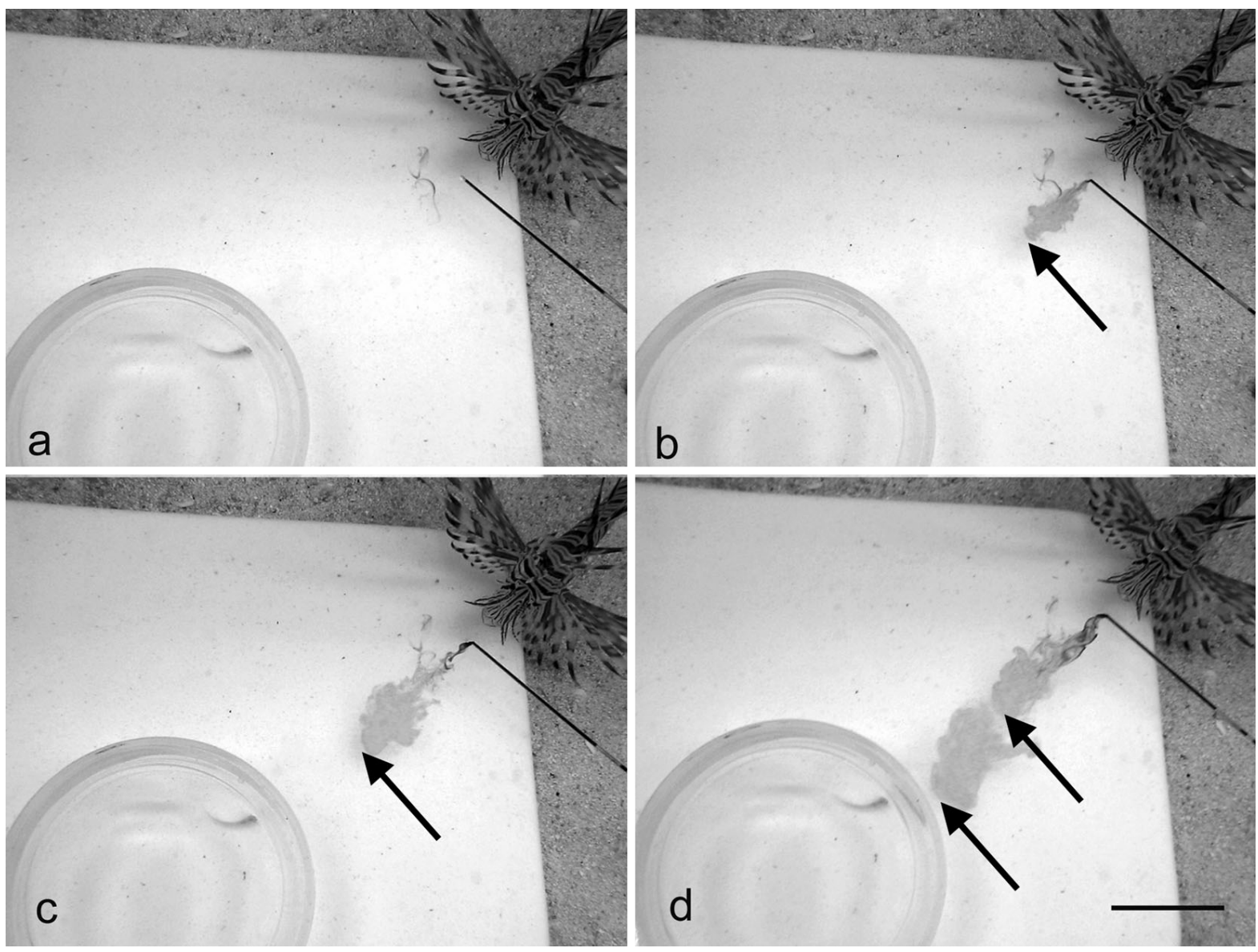

Fig. 1. Pterois volitans. (a-d) Sequence of still images captured from a video (Movie S1 available at www.intres.com/articles/suppl/m448p001_supp/) of a predatory lionfish producing a water jet directed toward a goby under a glass dish. Blue food-grade dye (grey in photo) was released from the end of a glass pipette in front of the lionfish to help visualize the water jet. Arrows indicate visible jet-fronts used to calculate distance and speed of pulses. Scale bar is $4 \mathrm{~cm}$ 
$t$-test: $t=2.96, \mathrm{df}=245.17, \mathrm{p}=0.003)$. Additionally, the production of water jets by lionfish in the field was more prevalent in their native Pacific, where $55.5 \%$ of hunting lionfish blew water jets at prey, than in the invaded Atlantic, where only $17.6 \%$ of hunting lionfish blew water jets $\left(\chi^{2}=37.36, \mathrm{df}=1, \mathrm{p}<0.001\right)$.

\section{Aquarium observations}

Lionfish produced directed water jets at goby prey in all aquarium trials $(n=8)$ in which the gobies were exposed to the lionfish (i.e. not protected in transparent container). Of these trials, 7 of 8 resulted in headfirst strikes. The single tail-first strike occurred when a relatively large lionfish attacked a relatively small goby. In 2 of the 7 trials resulting in head-first strikes, the lionfish continued blowing at the goby until the goby changed orientation to face the lionfish. In the other 5 trials resulting in head-first strikes, the lionfish continued blowing at the goby while simultaneously changing its own orientation to face the head of the goby. In each of these 7 trials, the lionfish struck at the head of the goby once the prey was positioned in a head-first orientation towards the mouth of the lionfish.

While approaching prey fish, lionfish produced an average of 18.5 water-jet pulses (range $=3$ to 62) before striking at the prey fish or apparently disengaging pursuit. On average, lionfish produced these pulsed jets at a rate of $2.3 \mathrm{~s}^{-1}$ (range $=1.2$ to $3.3 \mathrm{~s}^{-1}$ ). The maximum distance from the mouth of the lionfish that a visible jet-front reached was $9.6 \mathrm{~cm}$ (Fig. 1). The mean velocity of jet-fronts was $20.4 \mathrm{~cm} \mathrm{~s}^{-1}$ (range $=10.8$ to $34.8 \mathrm{~cm} \mathrm{~s}^{-1}$ ).

\section{DISCUSSION}

Water jets may increase the predation efficiency of lionfish in 2 potentially complementary ways. First, water jets may overwhelm the lateral line system of prey fishes, masking the signal associated with the predator's strike. Second, jets may increase the incidence of head-first capturing and swallowing. Fish typically orient facing into currents, thereby reducing drag and the energy required in maintaining position (Arnold 1974). Thus, a water jet may result in prey fish facing the approaching lionfish.

Head-first capture is advantageous for several reasons. The posterior orientation of dorsal, anal, and pelvic spines defend a potential prey fish from a caudal attack (spines reduce the likelihood of prey being swallowed). However, during a head-first strike, posteriorly pointing fin spines of the prey fish may actually reduce the chance of escape. For many piscivores, head-first strikes are more successful than tail-first attacks (Reimchen 1991), and the time elapsed between strike and complete swallowing is shorter for head-first strikes than for tail-first strikes, especially when prey are large relative to the size of the predator (Reimchen 1991, Nilsson \& Brönmark 1999). Additionally, esophageal abrasion of the predator is less likely to occur during head-first swallowing (Reimchen 1991).

Regardless of the specific function or combination of functions of water jets, it seems reasonable to conclude that they confer some advantage to the lionfish predator. Small lionfish appear to use this behavior more commonly than larger lionfish, and lionfish in the Pacific appear to use this behavior more commonly than those in the invaded Atlantic. It is likely that production of water jets is metabolically costly, and that they are only used when the cost of producing them is outweighed by the advantage that they confer. It makes sense that the advantage of water jets would be greater for small lionfish than for large lionfish when targeting similarly sized prey. It also makes sense that this advantage would be greater in the Pacific - where prey have co-evolved with lionfish and respond to them by taking evasive or defensive actions - than in the Atlantic, where prey are evolutionarily naïve to lionfish and are less likely to take appropriate evasive or defensive actions (A. Anton pers. comm.).

Most, if not all, teleost fishes display coughing behavior, in which water is expelled through the open mouth by buccal compression, thereby expelling indigestible or unpalatable items (Wainwright \& Turingan 1997). Several teleosts also display specialized blowing behavior, a modification of coughing in which the expelled water is forced through a partially closed mouth, creating a strong, directed jet of water (Wainwright \& Turingan 1997). The cranial muscle activities involved in coughing and blowing are very similar in tetraodontiform fishes and analyses suggest that blowing involves a simple evolutionary adaptation of the coughing mechanism (Wainwright \& Turingan 1997). Other species of predatory teleosts exhibit blowing behavior when uncovering, manipulating, and capturing marine (Frazer et al. 1991) and even terrestrial (Elshoud \& Koomen 1985) invertebrates. However, to our knowledge, lionfish are the only predator reported to display blowing behavior when capturing other fish. We conducted an extensive literature search using both Web of Science and Google Scholar with the keywords: lionfish, 
piscivory, blow, expel, feeding, suction, head-first, and cough (in a variety of combinations). We found no studies that documented blowing behavior or the production of water jets in any piscivore. This is particularly interesting given that the lionfishes Pterois volitans and $P$. russelli have been used as a model system to describe suction feeding in piscivores (Osse \& Muller 1980, Muller et al. 1982, van Leeuwen \& Muller 1984, Muller \& Osse 1984).

Traits of invasive predators not previously encountered by native prey may contribute to the success of predator invasions in a number of systems (Sih et al. 2010). If water-jet facilitated piscivory is indeed unique to the genus Pterois, Atlantic coral-reef fish prey have not encountered this predatory behavior during their evolutionary history, and therefore have not evolved effective behavioral or physiological antipredator responses. A lack of effective defensive responses in native prey may have contributed to the unprecedented success of invasive lionfish, and may exacerbate the direct negative effects of lionfish on native prey populations as well as the indirect negative effects of lionfish on competing native piscivores.

Acknowledgements. We thank M. Hixon and K. PageAlbins for reviewing the manuscript and K. Ambrose, T. Kindinger, R. Ng, C. O'Brian, J. Pearson, and G. Scheer for technical assistance. This work was supported by a National Science Foundation Graduate Research Fellowship awarded to M.A.A., an award from the W. M. Keck Foundation Program in Molecular Systematics and Evolution at the Natural History Museum of Los Angeles County to P.J.L., and a National Science Foundation research grant (0851162) to M. Hixon.

\section{LITERATURE CITED}

Albins MA, Hixon MA (2008) Invasive Indo-Pacific lionfish Pterois volitans reduce recruitment of Atlantic coral-reef fishes. Mar Ecol Prog Ser 367:233-238

Albins MA, Hixon MA (2011) Worst case scenario: potential long-term effects of invasive predatory lionfish (Pterois volitans) on Atlantic and Caribbean coral-reef communities. Environ Biol Fishes (in press). doi: 10.1007/s10641011-9795-1

Allen GR, Eschmeyer WN (1973) Turkeyfishes at Eniwetok. Pac Discovery 26:3-11

Arnold GP (1974) Rheotropism in fishes. Biol Rev Camb Philos Soc 49:515-576

- Elshoud GCA, Koomen P (1985) A biomechanical analysis of spitting in archer fishes (Pisces, Perciformes, Toxidae). Zoomorphology 105:240-252

Fishelson L (1997) Experiments and observations on food consumption, growth and starvation in Dendrochirus brachypterus and Pterois volitans (Pteroinae, Scorpaenidae). Environ Biol Fishes 50:391-403

Frazer TK, Lindberg WJ, Stanton GR (1991) Predation on sand dollars by gray triggerfish, Balistes capriscus, in the Northeastern Gulf of Mexico. Bull Mar Sci 48:159-164

> Green SJ, Côté IM (2009) Record densities of Indo-Pacific lionfish on Bahamian coral reefs. Coral Reefs 28:107

$>$ Holway DA, Suarez AV (1999) Animal behavior: an essential component of invasion biology. Trends Ecol Evol 14: 328-330

Kendall JJ Jr (1990) Further evidence of cooperative foraging by the turkeyfish Pterois miles in the Gulf of Aqaba, Red Sea, with comments on safety and first aid. Proc Am Acad Underwater Sciences Scientific Diving Symp 10: 209-223

Morris JA (2009) The biology and ecology of the invasive Indo-Pacific lionfish. PhD dissertation, North Carolina State University, Raleigh, NC, p 118-134

Morris JA, Akins JL (2009) Feeding ecology of invasive lionfish (Pterois volitans) in the Bahamian archipelago. Environ Biol Fishes 86:389-398

Morris JA, Whitfield PE (2009) Biology, ecology, control and management of the invasive Indo-Pacific lionfish: an updated integrated assessment. NOAA Technical Memorandum NOS NCCOS 99:1-57

Muller M, Osse JWM (1984) Hydrodynamics of suction feeding in fish. Trans Zool Soc Lond 37:51-135

Muller M, Osse JWM, Verhagen JHG (1982) A quantitative hydrodynamical model of suction feeding in fish. $\mathrm{J}$ Theor Biol 95:49-79

Nilsson PA, Brönmark C (1999) Foraging among cannibals and kleptoparasites: effects of prey size on pike behavior. Behav Ecol 10:557-566

Osse JWM, Muller M (1980) A model of suction feeding in teleostean fishes with some implications for ventilation. In: Ali MA (ed) Environmental physiology of fishes. Plenum Press, New York, NY, p 335-352

Randall JE, Allen GR, Steene RC (1990) Fishes of the Great Barrier Reef and Coral Sea. University of Hawaii Press, Honolulu

> Reimchen TE (1991) Evolutionary attributes of headfirst prey manipulation and swallowing in piscivores. Can J Zool 69:2912-2916

> Schiel DR, Kingsford MJ, Choat JH (1986) Depth distribution and abundance of benthic organisms and fishes at the subtropical Kermadec Islands. NZ J Mar Freshw Res 20:521-535

> Schofield PJ (2009) Geographic extent and chronology of the invasion of non-native lionfish (Pterois volitans [Linnaeus 1758] and P. miles [Bennett 1828]) in the Western North Atlantic and Caribbean Sea. Aquat Invasions 4: 473-479

Schofield PJ (2010) Update on geographic spread of invasive lionfishes (Pterois volitans [Linnaeus, 1758] and P. miles [Bennett, 1828]) in the Western North Atlantic Ocean, Caribbean Sea and Gulf of Mexico. Aquat Invasions 5: S117-S122

> Sih A, Bolnick DI, Luttbeg B, Orrock JL and others (2010) Predator-prey naïveté, antipredator behavior, and the ecology of predator invasions. Oikos 119:610-621

Sutherland WJ, Clout M, Cote IM, Daszak P and others (2010) A horizon scan of global conservation issues for 2010. Trends Ecol Evol 25:1-7

> van Leeuwen JL, Muller M (1984) Optimum sucking techniques for predatory fish. Trans Zool Soc Lond 37: 137-169

- Wainwright PC, Turingan RG (1997) Evolution of pufferfish inflation behavior. Evolution 51:506-518 